\title{
Endogenous and exogenous ARC in serum withdrawal mediated PC12 cell apoptosis: a new pro-apoptotic role for ARC
}

\author{
TA Dowds ${ }^{1}$ and EL Sabban ${ }^{\star, 1}$ \\ ${ }^{1}$ Department of Biochemistry and Molecular Biology, New York Medical \\ College, Valhalla, New York 10595, USA \\ * Corresponding author: Esther L Sabban, Department of Biochemistry and \\ Molecular Biology, New York Medical College, Valhalla, NY 10595, USA. \\ Tel: (914) 594-4068; Fax: (914) 594-4058; E-mail: Sabban@NYMC.edu
}

Received 27.9.00; revised 31.1.01; accepted 1.2.01

Edited by FD Miller

\begin{abstract}
The role of ARC (Apoptosis Repressor with Caspase Recruitment Domain) in PC12 cell serum withdrawal driven apoptosis was studied. A progressive and massive increase in ARC protein occurs during serum withdrawal that correlates with declining survival and processing of caspase-2, previously shown to associate with ARC. ${ }^{1}$ This accumulation of ARC occurs in a transcriptional and translational independent manner. Additionally, ARC is localized exclusively in the nucleus of PC12 cells. Furthermore, transfection of PC12 cells with hARC-Flag promotes death and fails to protect the cells from apoptosis by serum withdrawal. Therefore, ARC functions in a pro-apoptotic manner in PC12 cell serum withdrawal induced apoptosis. Cell Death and Differentiation (2001) 8, 640-648.
\end{abstract}

Keywords: ARC; caspase-2; PC12 cells; serum withdrawal; aggregation; apoptosis

Abbreviations: ARC, apoptosis repressor with caspase recruitment domain; Apaf-1, apoptotic protease activating factor-1; RAIDD, receptor interacting protein (RIP)-associated ICH-1/CED3 homologous protein with a death domain; FLIP, FLICE-inhibitory protein; Fadd, Fas-associated death domain; HEK 293T cells, human epithelial kidney 293T; PC12 cells; pheochromocytoma 12 cells; NGF, nerve growth factor

\section{Introduction}

Apoptosis, initiated by a variety of stimuli, utilizes well ordered signaling cascades leading to a morphologically distinct form of cell death. This process involves active participation of many different cellular components, ranging from the release of small regulatory molecules, such as Cytochrome $c$, to the activation of the caspases, a family of cysteine proteases that are ultimately responsible for the disassembly of the cell. Extremely important in the regulation of apoptotic events are molecules that contain homophilic domains, including the death domains (DD), death effector domains (DED) and the caspase recruitment domain (CARD), all consisting of six antiparallel $\alpha$-helices arranged in a similar three-dimensional conformation. $^{2-4}$ Typically, these molecules associate via like to like interactions (i.e. CARD-CARD) and can activate or inhibit apoptosis through interactions with initiator procaspases.

The activation of initiator caspases occurs largely through the sequestration (induced proximity) of the inactive zymogen through the homophilic domain contained within its pro-domain. For example, procaspases-2 and -9 are able to undergo CARD-CARD interactions with their respective adapter molecules, RAIDD and Apaf-1.5,6 This interaction promotes the proteolytic processing of initiator pro-caspases leading to the apical activation of apoptotic pathways. Alternatively, certain inhibitors of apoptosis, referred to as decoys, also have homophilic domains used to recruit caspases away from their activation site. ${ }^{7}$ For example, FLIP, a catalytically inactive caspase-8 like molecule with two DEDs, essentially titrates out the adapter molecule FADD. Consequently, pro-caspase-8 is not recruited to its site of activation resulting in the inhibition of apoptosis. ${ }^{8}$

One CARD-containing protein, now known as Apoptosis

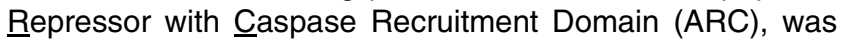
suggested to act as a repressor or decoy molecule, selective for certain initiator pro-caspases and thereby inhibit apoptosis. ${ }^{1}$ Our group originally cloned ARC from a rat PC12 cell cDNA library and found that its mRNA is expressed abundantly in heart, skeletal muscle and in some brain regions. ${ }^{9}$ Analysis of ARC's deduced amino acid sequence revealed a putative $\mathrm{N}$-terminal bipartite nuclear localization sequence within its CARD as well as an acidic domain with 16 tandem Glu-Pro dipeptide repeats at the C-terminal. The rat and human ARC proteins share $82 \%$ homology. ${ }^{1}$ Their CARDs have significant amino acid similarity to the CARDs from caspase-2, caspase-9, RAIDD and Apaf-1.

Previous studies indicating ARC's anti-apoptotic role were based on the exogenous delivery of human ARC. ${ }^{1,10}$ Alone ARC expression did not have any effect on the cell survival in HEK 293T cells, however, upon co-transfection with apoptotic triggering molecules, such as caspase-8, CED-3, CD95/Fas, TNFR1, Fadd or Tradd, ARC prevented death. ${ }^{1}$ ARC was detected in immunoprecipitates of caspase-2, caspase-8 or CED-3 but did not associate with caspase-1, caspase-3 or caspase-9. Furthermore, ARC decreased the enzymatic activity of caspase-8. Since ARC showed a selectivity for particular caspases, it was proposed that delivery of exogenous $A R C$ or the use of agents that would increase endogenous expression of ARC 
could potentially be administered to areas of injury or insult to prevent apoptosis. ${ }^{1}$

One potential drawback of transfection experiments, is the possibility that the abnormally high amounts of receptors and adapter molecules may lead to promiscuous homophilic association between domains that do not normally interact in the cell. ${ }^{11}$ Therefore, we decided to examine the role of endogenous $A R C$ in the wellcharacterized serum withdrawal model of PC12 cell apoptosis that is dependent on caspase-2 processing. The findings suggest that ARC may have differential roles and can function in a pro- or anti-apoptotic manner depending on the cell type or stimuli employed.

\section{Results}

\section{Expression of endogenous ARC}

The expression of $A R C$ was examined in several rat tissues by immunoblots (Figure 1A). A predominant $24.6 \mathrm{kDa}$ protein, that corresponded in size to the open reading frame from the full-length ARC cDNA, ${ }^{9}$ was observed in adrenal (cortex and medulla), heart, hippocampus but not in the spleen. Since ARC was originally cloned from a PC12 cell cDNA library, ${ }^{9}$ an adrenomedullary derived line, we examined if these cells express the ARC protein. A single $24.6 \mathrm{kDa} A R C$ species was
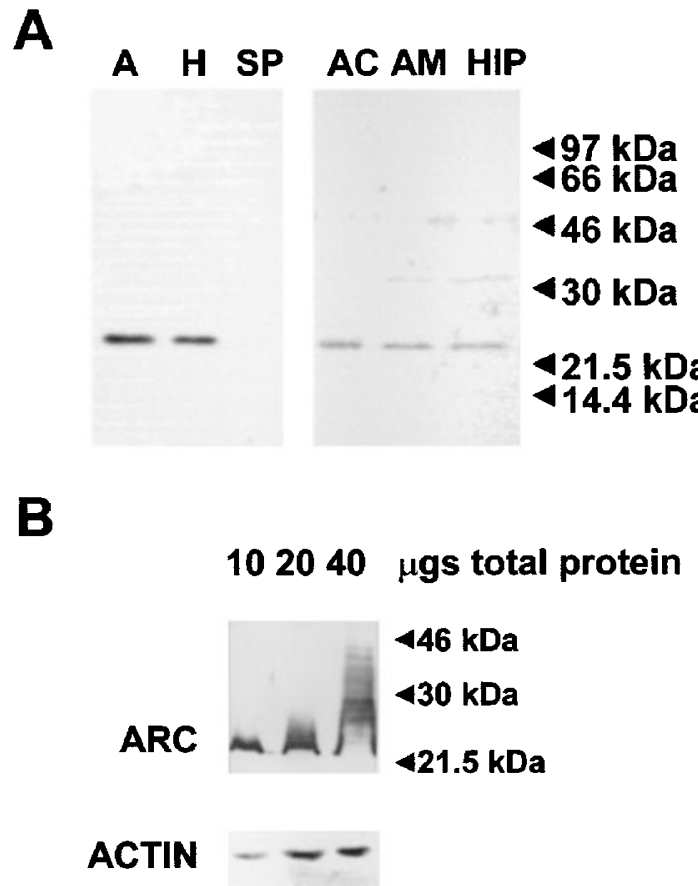

Figure 1 Expression of $\mathrm{ARC}$ protein in various rat tissues and in $\mathrm{PC} 12$ cells. (A) Immunoblots of $20 \mu \mathrm{g}$ of tissue homogenates detected with ARC antibody. Abbreviations: A, adrenal; $H$, heart; SP, spleen; $A C$, adrenal cortex; AM, adrenal medulla; HIP, hippocampus. (B) Immunoblot of $10,20,40 \mu \mathrm{g}$ of total protein from control PC12 cell lysates harvested in RIPA buffer supplemented with $2 \%$ SDS followed by probe sonication and boiling for $2 \mathrm{~min}$. Blot was initially detected with the ARC antibody and reprobed with actin to assure normal protein migration also detected in PC12 cell homogenates $(10-20 \mu \mathrm{g})$ (Figure 1B).

At a high homogenate concentration $(40 \mu \mathrm{g})$ ARC displayed pronounced aberrant migration consistently observed on immunoblots from SDS-PAGE electrophoresis (Figure 1B). A number of higher apparent molecular weight bands were observed with a discrete 'ladder' migration. Most of these apparent molecule weights do not approach that of an ARC dimer ( $\sim 50 \mathrm{kDa})$. The result suggests that $A R C$ may be aggregating via a CARD-CARD interaction with other CARD-containing proteins. Interestingly, at high protein concentration, in extracts from adrenal medulla, ARC is primarily a discrete band of $24.6 \mathrm{kDa}$. The difference in migration between adrenal medulla and PC12 cells could reflect differences in the expression of homophilic domain-containing molecules.

To assure that the laddered migration observed in PC12 cells at high protein concentration was unique to $A R C$ and not due to an artifact of the gel electrophoresis, the blot was stained with Ponceau $S$ and the overall total protein migration was normal (data not shown). When the blot was reprobed with antisera to actin, it did not display aberrant migration (Figure 1B). In addition, increasing the SDS concentration in the samples, sonication or extended boiling did not alter ARC's ladder migration at the higher protein concentrations.

It is important to note that the ARC antibody, raised against a synthetic peptide [(Glu-Pro $\left.{ }_{14} \mathrm{Glu}\right]$ designed to recognize the acidic Glu-Pro tandem repeat at the $C$ terminus, was very sensitive. In fact, it was able to detect the $24.6 \mathrm{kDa}$ species in as little as $5 \mu \mathrm{g}$ of total PC12 cell homogenates. In addition, we compared several commercially available ARC antibodies that could detect the ARC protein only at the highest protein concentration $(40 \mu \mathrm{g})$ (data not shown).

\section{ARC protein accumulation in the caspase-2 dependent serum withdrawal model of apoptosis}

Having established that $A R C$ is expressed in PC12 cells, we next aimed to study its endogenous regulation in the PC12 cell serum withdrawal model of apoptosis. Previous studies using caspase inhibitors and antisense to caspase-2 established that this model is dependent on caspase-2 for apoptosis. $^{12-14}$ Using a model that required caspase-2 processing for death was especially appropriate because earlier studies demonstrated a physical association between ARC and caspase-2. ${ }^{1}$

In our experiments, undifferentiated PC12 cells were subjected to serum withdrawal for various times up to $72 \mathrm{~h}$. Consistent with previous reports, ${ }^{15}$ there was a progressive decline in cell survival (Figure 2A). By $6 \mathrm{~h}$ serum withdrawal $\sim 20 \%$ of the cells did not survive. This progressed to $\sim 60 \%$ death by $24 \mathrm{~h}$ and almost all the cells failed to survive by $72 \mathrm{~h}$ serum withdrawal.

As expected the progression of death in the cultures correlated with caspase-2 processing (Figure 2B). Caspase-2 processing was examined at various times of serum withdrawal by immunoblots using an antisera against the large subunit. This antisera detects both the precursor as 
well as the large subunit (p18) of the active enzyme tetramer. The levels of the p46 precursor of caspase-2 declined over the time course. The p18 large subunit, was evident by $6-12 \mathrm{~h}$ and increased with the duration of serum withdrawal.

The levels of ARC protein were determined by immunoblots from the same homogenates (Figure 3 ).

\section{A}

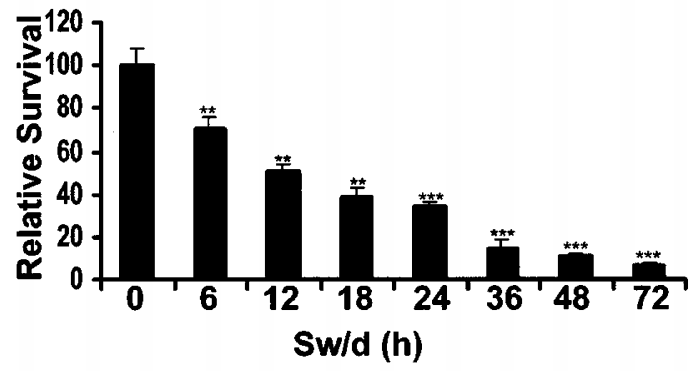

B

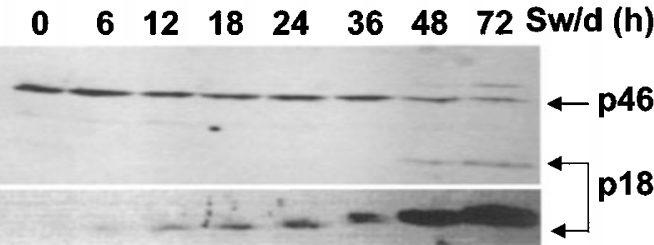

Figure 2 PC12 cell apoptosis at various times of serum withdrawal (Sw/d). (A) PC12 cell survival at $0,6,12,24,48,72 \mathrm{~h} \mathrm{Sw/d}$ was determined by counting the number of intact nuclei, as described in Materials and Methods. Survival was reported relative to the number of intact nuclei at the start of Sw/d and is the mean \pm S.E.M. $(n=6){ }^{* *}$ Is $P<0.01$ and ${ }^{* * *}$ is $P<0.001$ compared to $0 \mathrm{~h} \mathrm{Sw} / \mathrm{d}$. (B) Caspase-2 processing was examined using Western blot analysis of $20 \mu \mathrm{g}$ total protein from PC12 cells at $0,6,12,24,48,72 \mathrm{~h} \mathrm{Sw} / \mathrm{d}$ followed by detection with the caspase-2 polyclonal antibody. A short exposure (top panel) and a longer exposure of the p18 band (bottom panel) of the same blot are presented to emphasize the accumulation

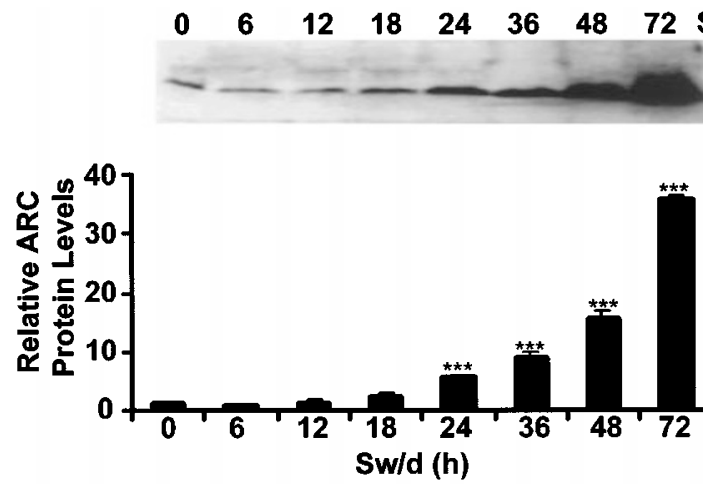

Figure 3 Accumulation of ARC protein in PC12 cells during serum withdrawal. Immunoblots of $5 \mu \mathrm{g}$ of total PC12 cell lysates after at $0,6,12$, 18, 24, 36, 48, $72 \mathrm{~h} \mathrm{Sw/d} \mathrm{detected} \mathrm{with} \mathrm{ARC} \mathrm{antibody.} \mathrm{A} \mathrm{representative}$ immunoblot of ARC during the time course of Sw/d and summary data after scanning the ARC immunoreactivity (mean \pm S.E.M.) $n=3$. ${ }^{* * *}$ Is $P<0.001$ compared to $0 \mathrm{~h} \mathrm{Sw} / \mathrm{d}$. The time course was performed four times in triplicate with similar results
Surprisingly, the results reveal a progressive and massive increase in ARC protein levels during serum withdrawal. By $24 \mathrm{~h}$ of serum withdrawal there was a significant (about fivefold) rise in ARC, which further increased over time. After 48 and $72 \mathrm{~h}$ of serum withdrawal ARC levels were about 20- and 40-fold higher, respectively, then in the untreated cells.

\section{Addition of NGF at the time of serum withdrawal decreases the ARC accumulation and caspase-2 processing}

Several agents that were shown to promote survival during serum deprivation, including NGF, bcl-2 and cAMP analogs, abrogate caspase- 2 processing. ${ }^{12}$ In light of these results, we decided to examine if this accumulation of ARC would be attenuated by addition of NGF at the time of serum withdrawal. Basal ARC levels were not affected by $100 \mathrm{ng} /$ $\mathrm{ml} \mathrm{NGF}$ treatment (Figure 4). However, NGF addition at the time of serum withdrawal increased cell survival, although it did not completely rescue the cells under these conditions (data not shown). In line with this, the caspase-2 processing in these serum-deprived cultures was reduced in the presence of NGF (Figure 4). Concomitantly, the presence of NGF significantly reduced the serum withdrawal elicited rise in ARC protein levels (Figure 4). These results, together with the previous experiment, indicate that the increase in $A R C$ is
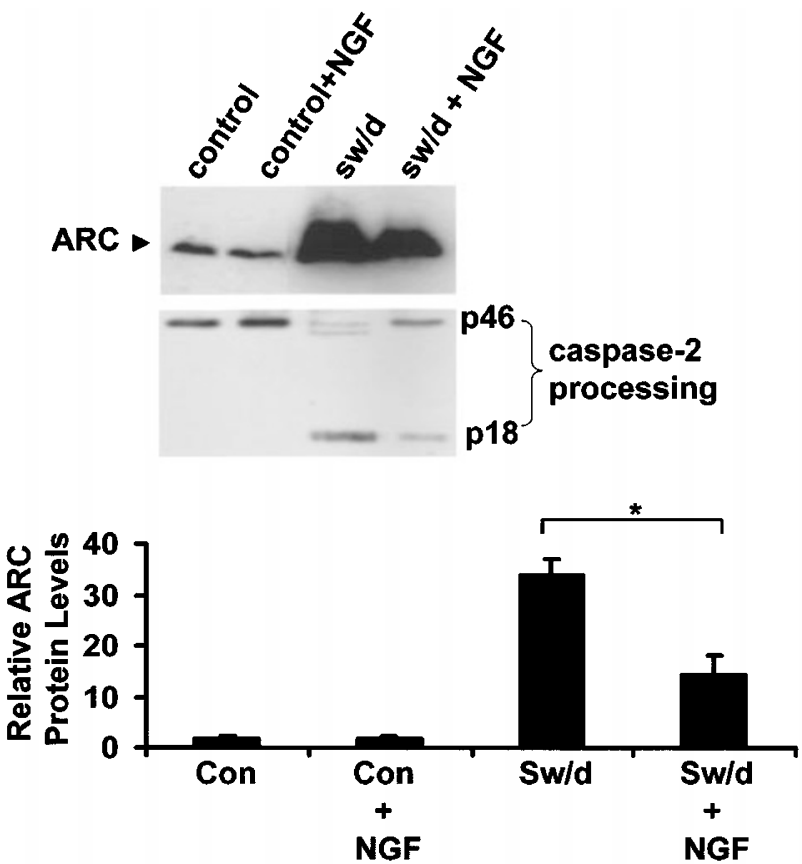

Figure 4 NGF decreased caspase-2 processing and accumulation of ARC during serum withdrawal. Cells were exposed to Sw/d for $48 \mathrm{~h}$ with or without $100 \mathrm{ng} / \mathrm{ml} \mathrm{NGF}$ added at the time of Sw/d. Representative immunoblots of $5 \mu \mathrm{g}$ total protein from cells was detected with ARC antibody (top panel) and of $20 \mu \mathrm{g}$ total protein detected with caspase-2 (bottom panel). Summary data after scanning ARC immunoreactivity (mean \pm S.E.M.) $n=3$. * Is $P<0.05 \mathrm{Sw} / \mathrm{d}$ $v s \mathrm{Sw} / \mathrm{d}+\mathrm{NGF}$. Experiments were carried out two times in triplicate with similar results 
correlated with decreased cell survival and caspase-2 processing.

\section{Accumulation of ARC protein was not accompanied by an increase in ARC mRNA}

The increase of ARC protein observed during apoptosis could result from elevated transcription, translation, and/or increases in protein stability. Northern blot analysis with ARC cDNA revealed a major $1.8 \mathrm{~kb}$ mRNA and a minor $\sim 5.0 \mathrm{~kb}$ species (Figure 5A). These sizes agree with what was previously reported in rat tissues. ${ }^{9}$ In human tissues, however, a major $\sim 1.0 \mathrm{~kb}$ ARC mRNA is reported as well as a minor $5.5 \mathrm{~kb}$ form. ${ }^{1}$ Since similar proteins are deduced in both species (221 and 208 amino acids respectively for rat and human), the discrepancies in the size of the major band likely result from differences in their untranslated regions.

Next, ARC mRNA levels were determined by performing Northern blot analyses of PC12 cells, untreated and after $24 \mathrm{~h}$ serum withdrawal (Figure $5 \mathrm{~B}$ ). Similar to a previous report, ${ }^{16}$ where the yield of poly $A^{+}$mRNA declines precipitously after $24 \mathrm{~h}$ of serum withdrawal, the amount of poly $\mathrm{A}^{+}$mRNA recovered delined markedly over the time of serum withdrawal. To compensate for this decline, four times as many cells were required to attain similar yield as from control cells. Equal amounts of poly $\mathrm{A}^{+} \mathrm{mRNA}(4 \mu \mathrm{g}$

A

\section{B}

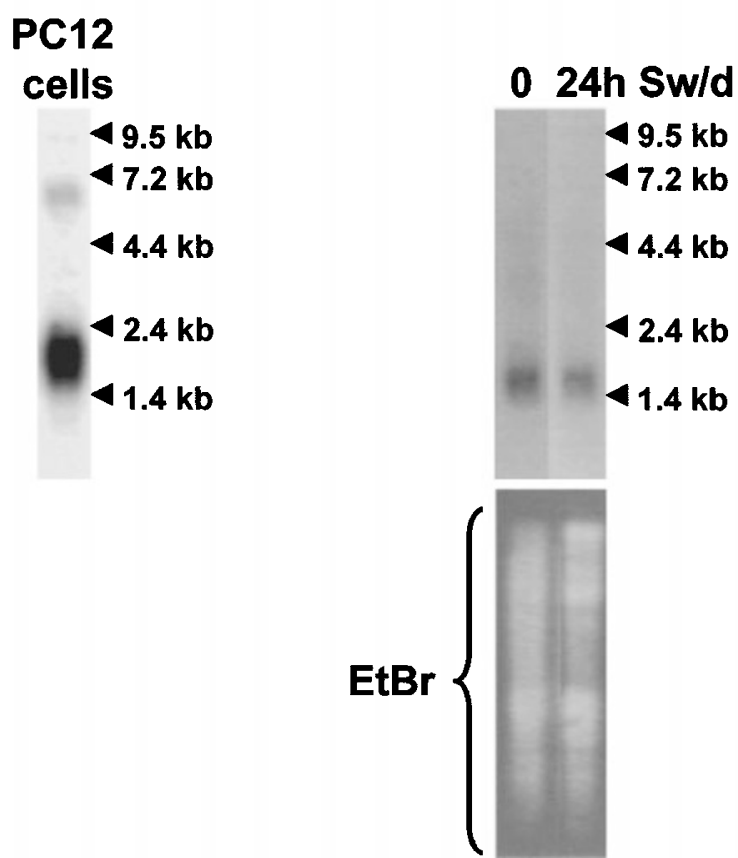

Figure 5 ARC mRNA does not increase during serum withdrawal. Representative Northern blots of $(A)$ poly $A^{+}$mRNA isolated from untreated PC12 cells and (B) (top) of poly $\mathrm{A}^{+}$mRNA from PC 12 cell during 0 and $24 \mathrm{~h}$ $\mathrm{Sw} / \mathrm{d}$ and (bottom) ethidium bromide staining of the gel before transfer to membrane. All blots were hybridized to a rat ARC cDNA (nucleotides 11 to 252) based on $A_{260}$ ) were analyzed by Northern blot (Figure $5 B$, top panel). Ethidium bromide staining assured that serum withdrawal, though significantly decreased the yield of poly $A^{+}$mRNA, did not effect the quality of the poly $A^{+}$mRNA in comparison to control (Figure $5 \mathrm{~B}$, bottom panel). $\mathrm{ARC}$ mRNA levels (per $\mu \mathrm{g}$ poly $\mathrm{A}^{+}$mRNA) were similar in the samples under both conditions. Thus, the marked accumulation of $A R C$ protein during serum withdrawal cannot result from increased ARC mRNA.

\section{ARC accumulation during serum withdrawal occurs in a transcriptional and translational independent manner}

To further characterize the mechanism of the accumulation of ARC protein during serum withdrawal, PC12 cells were treated with the transcriptional and translational inhibitors, actinomycin $\mathrm{D}$ and cycloheximide, respectively. The cultures were treated for $24 \mathrm{~h}$ (first time point of significant rise in ARC protein, Figure 3) with $2 \mu \mathrm{g} / \mathrm{ml}$ actinomycin D or $5 \mu \mathrm{g} / \mathrm{ml}$ cycloheximide in the presence or absence of serum and cell survival assessed (Figure 6A). After $24 \mathrm{~h}$, actinomycin D in the presence of serum was slightly toxic. However, treatment with actinomycin D or cycloheximide did not abrogate apoptosis during serum withdrawal. This finding is consistent with earlier reports that undifferentiated PC12 cells undergo apoptosis in a transcriptional and translational independent manner during serum withdrawal. ${ }^{17,18}$ In fact, when exposed to $24 \mathrm{~h}$ serum deprivation in the presence of actinomycin $\mathrm{D}$ or cycloheximide, less than $10 \%$ of the cell survived, compared to about $50 \%$ survival without the inhibitors (Figure $6 \mathrm{~A}$ ). Similar to these results, inhibition of RNA and protein

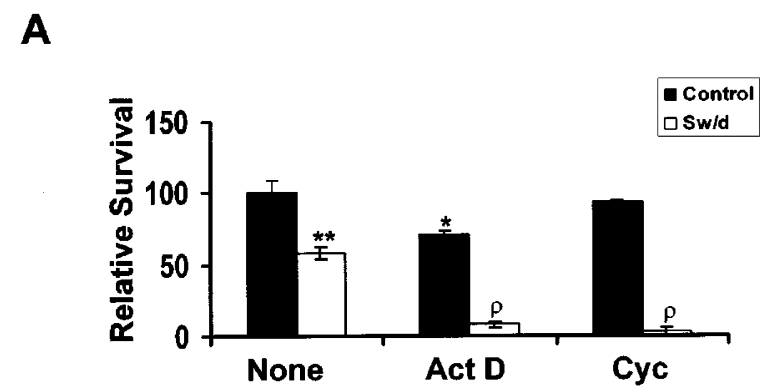

B

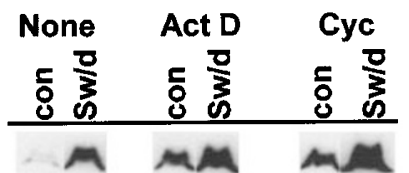

Figure 6 Inhibitors of transcription and translation do not prevent the accumulation of ARC protein. (A) PC12 cell survival was assessed by counting the number of intact nuclei in PC12 cells with no addition (None) or with $2 \mu \mathrm{g} /$ $\mathrm{ml}$ actinomycin $\mathrm{D}($ Act $\mathrm{D}$ ) or $5 \mu \mathrm{g} / \mathrm{ml}$ cycloheximide (Cyc) in the presence (Control) or the absence of serum (Sw/d) for $24 \mathrm{~h}$. Mean \pm S.E.M. $(n=3)$. * Is $P<0.05$ and $^{* *}$ is $P \leqslant 0.01$ as compared to control, $\rho$ is $P<0.001 \mathrm{vs} \mathrm{Sw/d}$ alone. (B) Representative immunoblot of $5 \mu \mathrm{g}$ total protein with ARC antibody under the above conditions 
synthesis is reported to enhance PC12 cell death by serum withdrawal. ${ }^{17}$

The levels of ARC protein were examined by immunoblot analysis in these cultures (Figure 6B). Interestingly, even in the presence of serum both actinomycin $D$ and cycloheximide increased basal ARC protein levels. Serum withdrawal lead to a further accumulation of ARC in the presence of these inhibitors. These results indicate that the accumulation of ARC occurs in a post-translational manner, and likely results from increased ARC stability. This might lead to aggregation of $A R C$ as its concentration in the nucleus increases.

\section{Co-localization of ARC and pro-caspase-2 in the nucleus of untreated PC12 cells}

The findings that endogenous ARC levels were robustly elevated during serum withdrawal led us to determine ARC's subcellular localization in the PC12 cells. The deduced ARC amino acid sequence revealed that both rat and human $A R C$ contain a putative bipartite nuclear localization signal, that could drive ARC's localization to the nucleus. ${ }^{9}$ Interestingly, several pro-caspases, including pro-caspase-2, have been reported in the nucleus of several cell types. ${ }^{19-21}$

When untreated PC12 cell homogenates were subjected to crude subcellular fractionation followed by Western blot

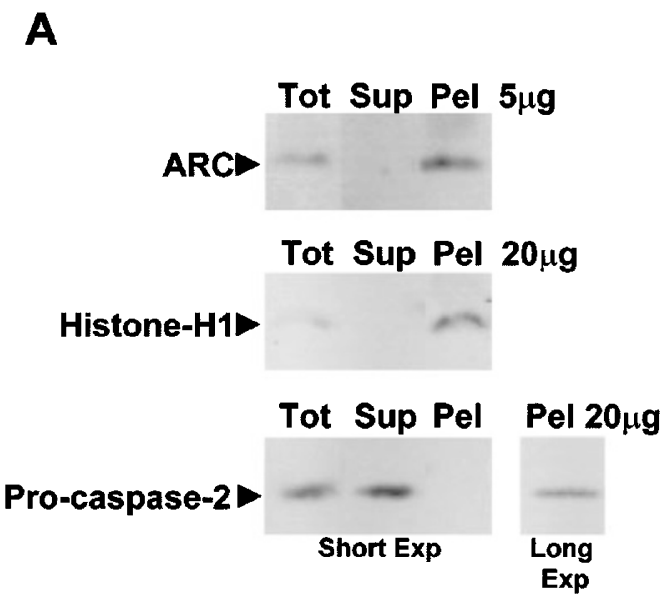

B

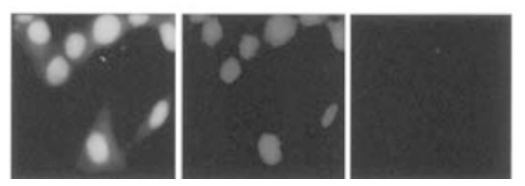

Figure 7 Nuclear localization of ARC and pro-caspase-2 in untreated PC12 cells. (A) Representative immunoblot of $5 \mu \mathrm{g}$ of total PC12 cell lysate (Tot), post-nuclear supernatant (Sup) and crude nuclear pellet (Pel) detected with the ARC antibody (Top panel). Twenty $\mu \mathrm{g}$ of total PC12 cell lysate (Tot), post nuclear supernatant (Sup) and crude nuclear pellet (Pel) detected with histone- $\mathrm{H} 1$ antibody (middle panel) and reprobed with the caspase-2 antibody (bottom panel). (B) Immunofluorescence microscopy detection of ARC protein in PC12 cells. The cells were stained with DAPI (left) and ARC antisera (center) of the same field. Preimmune sera (right) analysis, the ARC protein was found enriched in the nuclear pellet, and was not detected in the post-nuclear supernatant (Figure 7A). Samples from the same fraction were analyzed with histone- $\mathrm{H} 1$ antibody. This revealed that histone- $\mathrm{H} 1$ was found only in the total cell lysate and enriched in the nuclear pellet. No histone- $\mathrm{H} 1$ was detected in the post-nuclear supernatant indicating no nuclear components contaminated the post-nuclear supernatant. Furthermore, this blot was striped and reprobed with the caspase-2 antibody. Pro-caspase-2 (p46) was largely found in the post-nuclear supernatant. Longer exposure also detected pro-caspase-2 in the nuclear pellet (Figure 7A), lending support that pro-caspase-2 may be partially colocalized with ARC in the nucleus.

To further confirm that the ARC protein is found in the nucleus of PC12 cells, immunofluorescence microscopy was used (Figure 7B). The ARC immunoreactivity was detected predominantly, if not exclusively, in the nucleus and overlapped with DAPI nuclei staining. The immunofluorescence microscopy left the possibility that ARC could have a peri-nuclear localization, therefore confocal microscopy was performed which further confirmed that ARC is localized to the nucleus of PC12 cells (data not shown).

\section{Transfection of exogenous ARC}

The accumulation of ARC protein during PC12 cell serum withdrawal mediated apoptosis called into question the putative role of $A R C$ as a repressor in this model. To further examine this, we tested the hypothesis that exogenous ARC may prevent apoptosis, as it did in HEK $293 \mathrm{~T}$ cells. ${ }^{1} \mathrm{We}$ performed transient transfections using hARC-Flag, the same construct used by Koseki et al. ${ }^{1}$ in HEK 293T cells, and determined its effect on PC12 cell survival. Surprisingly, we found that transfection of hARC-Flag triggered substantial PC12 cell death compared to the cells transfected with the

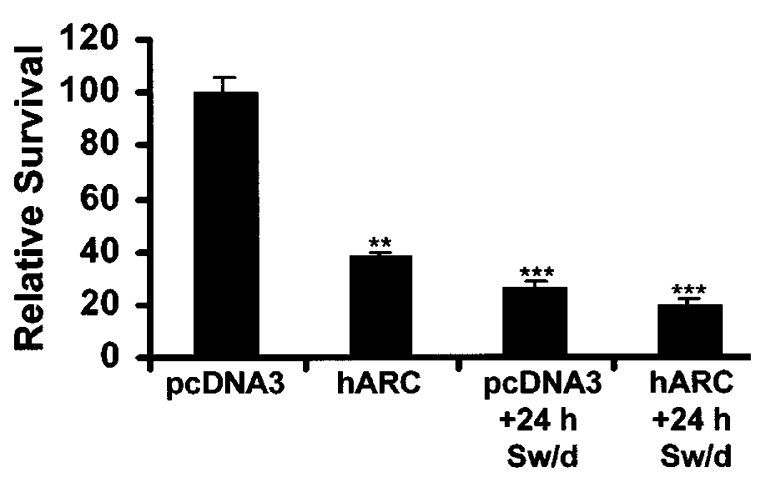

Figure 8 Transfection with hARC-Flag elicited PC12 cell death and failed to protect the cells from $24 \mathrm{~h}$ serum withdrawal. As described in Materials and Methods, the PC12 cells were transfected with either pcDNA3 or pcDNA3hARC-Flag ( $h A R C$ ) for $24 \mathrm{~h}$ in the presence of serum. Some cells were then subjected to $24 \mathrm{~h} \mathrm{Sw} / \mathrm{d}$ (pcDNA3+24h Sw/d, hARC+24h Sw/d) or remained in the presence of serum (pcDNA3 or hARC) for $24 \mathrm{~h}$. Relative cell survival was assessed $48 \mathrm{~h}$ after the start of transfection where the mean \pm S.E.M. $(n=3) .{ }^{* *}$ Is $P<0.01$ and ${ }^{* *}$ is $P<0.001$ compared to control. Experiment was carried out two times in triplicate with similar results 
empty vector (pcDNA3). In fact less than $40 \%$ of the cells survived when transfected with hARC-Flag (Figure 8). Addition of NGF did not significantly change the extent of ARC elicited cell death (data not shown).

Furthermore, when the PC12 cells transfected with hARC-Flag were subjected to serum withdrawal, there was no reduction in apoptosis (Figure 8). The extent of survival in response to $24 \mathrm{~h}$ serum withdrawal tended to be lower in the cultures transfected with the hARC-Flag expression vector. This suggests that in PC12 cells, ARC is pro-apoptotic and does not repress serum withdrawal driven apoptosis.

\section{Discussion}

The present study reveals that ARC promotes PC12 cell death and does not rescue these cells from serum withdrawal driven apoptosis. This might explain why the massive accumulation of endogenous ARC, that correlated with the progression of cell death and the processing of caspase-2 during serum withdrawal, does not protect the cells from death. Furthermore, the accumulation of ARC protein during serum withdrawal occurs in a transcriptional and translational independent manner. This suggests that post-translational modifications and/or alterations in the protein degradation pathways during apoptosis account for ARC's massive accumulation. In this regard, ARC does have a number of putative phosphorylation sites throughout the length of the protein $^{9}$ that could potentially be targeted during serum withdrawal and cause an increase in ARC's protein stability. The accumulation may also be aided through a decrease in ARC protein turnover, as there are a number of studies indicating that certain protein degradation pathways have decreased activity during apoptosis. ${ }^{22}$ Moreover, ARC, like other CARD-containing molecules, appears to aggregate under increasing protein concentrations. Therefore, a decreased degradation of ARC may lead to its initial accumulation in the condensing apoptotic nuclei that drives its aggregation. In turn, the aggregation of ARC might subsequently protect it from degradation.

The formation of aggregates and of filamentous structures has been proposed to play an important role in apoptosis. These structures are capable of recruiting adapter proteins and pro-caspases, leading to caspase activation and apoptosis. ${ }^{23}$ In this regard, it has been shown that endogenous caspase- 8 is recruited by polyglutamine inclusions in neurons that result in the activation of caspase- 8 and subsequent apoptosis. ${ }^{24}$ Also, the over-expression of FADD, pro-caspase-8 adapter molecule, leads to the formation of death effector filaments (DEFs) that can recruit caspase- 8 and induce its activation. ${ }^{23,25}$ Similarly, over-expression of the CARD of RAIDD, pro-caspase-2 adapter molecule, forms filamentous structures that may be similar to DEFs. ${ }^{19}$ It was suggested that the conformation of RAIDD, where the CARD may tightly associate with the DD, could modulate its ability to form filaments. It is possible that over-expression of the adapter molecules may lead to association between homophilic domains that do not normally occur under physiological conditions in the cell. ${ }^{11}$
Our results suggest it is conceivable that high concentrations of endogenous CARD-containing molecules accumulate during serum withdrawal driven apoptosis, as we have observed not only massive increases in ARC protein but also for other CARD-containing molecules. Recently, many apoptotic molecules containing CARDs and DDs have been localized in the nucleus. ${ }^{10,21,26-28}$ Therefore, the condensing apoptotic nucleus is an appropriate environment that would promote ARC aggregate formation with itself and with other CARD-containing proteins.

Along these lines, the generation of an aggregate during serum withdrawal may explain why the massive accumulation of ARC, especially at later time points, correlates with the most predominant caspase-2 processing. We found that though pro-caspase-2 was predominantly in the cytosol, there was a small, but significant, amount present in the nucleus of PC12 cells. This finding is supported by several other studies that have shown that caspase-2 is localized in several subcellular compartments including the nucleus ${ }^{19-21}$ and that the pro-domain of caspase-2 directs its nuclear localization. ${ }^{29}$ The co-localization of ARC with pro-caspase-2 in PC12 cells, could enable a CARD-CARD interaction as observed in previous studies. ${ }^{1}$ Moreover, it has been speculated that at the onset of apoptosis the initial processing of caspase-2 occurs in the nucleus, and only later in the cytosol. ${ }^{19}$ The nuclear co-localization of ARC and pro-caspase-2 in PC12 cells would not only enable a potential endogenous interaction triggering early caspase-2 processing, but under apoptotic conditions the nuclear accumulation of ARC could drive its aggregation. These aggregates might act similarly to DEFs, promoting further caspase-2 processing as seen at the later serum withdrawal time points, $24-72 \mathrm{~h}$. It remains to be determined whether the CARD and/or the Glu-Pro rich Cterminal acidic domains of ARC are involved in the formation of aggregates or if other proteins are required.

The formation of ARC aggregates, as well as, ARC's localization in several brain regions might enable it to be involved in the regulation of neurodegenerative processes. The present study utilized mitotic undifferentiated PC12 cells that undergo apoptosis in a transcription and translation independent manner. Therefore, it remains to be determined whether or not neuronally differentiated PC12 cells, post-mitotic in nature, regulate ARC in a similar fashion since they undergo apoptosis in a transcription and translation dependent manner.

We previously observed abundant ARC mRNA in several rat brain regions including the cerebrum, cerebellum, and medulla. ${ }^{9}$ In contrast homogenates of whole human brain did not reveal any ARC hybridization, ${ }^{1}$ suggesting that $A R C$ is localized in specific brain regions and is diluted in whole brain mRNA. The observation of the ARC protein in the hippocampus, a region affected in Alzheimer's disease is intriguing. A recent study suggests that activation of caspase- 2 is required for $\beta$-amyloid triggered cell death in PC12 cells, as well as in sympathetic and hippocampal neurons. ${ }^{30}$ In addition, neurons from caspase-2 null mice were totally resistant to $\beta$-amyloid - $_{1-42}$ toxicity. $^{30}$ Interestingly, ARC could possibly 
be regulating caspase- 2 processing during $\beta$-amyloid am-42 $_{1}$ toxicity.

Our results also imply that based on the cell type or stimuli employed, ARC can have differential roles and function in a pro- or anti-apoptotic manner. When transfected into PC12 cells, hARC-Flag was pro-apoptotic, whereas, transfection of hARC-Flag alone into HEK 293T cells had no effect on survival. ${ }^{1}$ ARC may be mediating this death of PC12 cells through activation of pro-caspase-2. It has been shown that HEK 293T cells express relatively lower levels of caspase-2 in comparison to Hela cells, ${ }^{19}$ while caspase- 2 appears abundant in PC12 cells. Therefore, solely on the basis of cell type, there is a difference in the expression of apoptotic substrates (i.e. pro-caspases) present, possibly leading to the differential effect seen with ARC. In addition, because different stimuli trigger different apical caspases, the type of stimuli employed may also determine if ARC functions in a pro- or anti-manner. hARCFlag did not protect the PC12 cells from serum withdrawal driven apoptosis, whereas, it did protect the HEK 293T cells from co-transfection of molecules that largely exert their apoptotic effect through caspase-8. ${ }^{1}$ Therefore, ARC may have the potential for development as a selective therapeutic agent, depending on the particular cell type used or apical caspase cascade triggered.

\section{Materials and Methods}

\section{Cell culture}

PC12 cells ${ }^{15}$ were cultured in DMEM supplemented with $10 \%$ fetal bovine serum, $5 \%$ donor horse serum, $50 \mu \mathrm{g} / \mathrm{ml}$ streptomycin, and $50 \mathrm{IU} / \mathrm{ml}$ penicillin in a humidified atmosphere at $37^{\circ} \mathrm{C}$ and $7 \% \mathrm{CO}_{2}$ as previously described. ${ }^{31}$ For serum withdrawal studies, cells were washed three times with serum-free medium, replated at a density of $1 \times 10^{6}$ cells per $100 \mathrm{~mm}$ dish and cultured for various amounts of time. In some experiments, $100 \mathrm{ng} / \mathrm{ml}$ mouse $\beta$-NGF (AUSTRAL Biologicals) was added at the time of serum withdrawal. For inhibition of transcription or translation, cells were pre-treated for $30 \mathrm{~min}$ with $2 \mu \mathrm{g} / \mathrm{ml}$ actinomycin D (Sigma) or $5 \mu \mathrm{g} / \mathrm{ml}$ cycloheximide (Sigma) prior to induction of serum withdrawal. The serum withdrawal washes for these experiments were carried out in the presence of the inhibitors. The concentration of actinomycin D used was based on a study carried out by Pittman et al. ${ }^{32}$ Whereas, in preliminary experiment, treatment with 5 or $10 \mu \mathrm{g} / \mathrm{ml}$ cycloheximide for $24 \mathrm{~h}$ was found to inhibit greater than $90 \%$ of the incorporation of the ${ }^{35} \mathrm{~S}$ methionine into total protein when compared to control cultures.

Following the treatments, cells were collected by centrifugation and resuspended in PBS containing 1\% NP-40, 0.5\% sodium deoxycholate, and $0.1 \%$ SDS and a cocktail of protease inhibitors including $1.0 \mu \mathrm{g} / \mathrm{ml}$ each of leupeptin (Sigma), aprotinin (Sigma), pepstatin A (Boehringer Mannheim), and $1 \mathrm{mM}$ phenylmethylsulfonyl fluoride (Sigma) (RIPA buffer). Following three times freeze/thaw the solution was put through a 28 gauge syringe and protein concentrations were determined by Lowry method (BioRad Dc protein assay).

\section{Subcellular fractionation}

Cells were lyzed by freeze/thaw in $20 \mathrm{mM}$ Tris- $\mathrm{HCl} \mathrm{pH} 7.9,1 \mathrm{mM}$ EDTA, $1 \mathrm{mM}$ EGTA, $90 \mathrm{mM} \mathrm{KCl}, 5 \mathrm{mM} \mathrm{MgCl} 2,10 \%$ glycerol, $0.5 \%$
NP-40 plus the protease inhibitors ( $\mathrm{N}$ buffer). An aliquot was removed as total cell lysate. The homogenate was centrifuged for $10 \mathrm{~min}$ at $3500 \times g$ and the post-nuclear supernatant and pellet fractions were collected. Pellet (crude nuclear fraction) was suspended in N-buffer, and all fractions were sheared by multiple passages through 28 gauge needle.

\section{Immunoblot analysis}

Protein homogenates from PC12 cells or various rat tissues were analyzed by immunoblots. The rat tissues, initially snap frozen in liquid nitrogen, were homogenized using a Polytron (Brinkman) in RIPA buffer, and processed similar to PC12 cell lysates.

Protein samples were resolved by $12 \%$ SDS-PAGE and transferred onto supported nitrocellulose membranes (BioRad). The membranes were blocked in 5\% non-fat milk, TBST $(50 \mathrm{mM}$ Tris, $\mathrm{pH}$ $7.5,500 \mathrm{mM} \mathrm{NaCl}, 0.05 \%$ Tween). They were then probed with primary antisera in $5 \% \mathrm{BSA}$, TBST overnight at $4{ }^{\circ} \mathrm{C}$. This was followed by a $2 \mathrm{~h}$ incubation with secondary antibody conjugated to horseradish peroxidase, goat anti-rabbit IgG or mouse anti-goat IgG (Pierce), in a $5 \%$ non-fat milk, TBST, and visualization was carried out using the Super Signal Chemiluminescence Substrate (Pierce).

The autoradiographic images were captured with a CCD camera (Datavision). In some cases, the amount of ARC protein was quantified by performing densitometric analyses within the linear range of each captured signal by using the Image Pro Plus software (Media Cybernetics). Statistical significance was determined by ANOVA followed by pairwise comparisons.

\section{Primary antibodies}

A rabbit polyclonal antibody was raised for ARC against a synthetic peptide for [(Glu-Pro) ${ }_{14} \mathrm{Glu}$ ]. A rabbit polyclonal (Nedd-2 p12, C-20) against the large subunit of caspase-2 and a goat polyclonal actin (C11) antibody were obtained from Santa Cruz Biotechnology, Inc. The monoclonal histone-H1 antibody was obtained from Chemicon.

\section{Immunofluorescence microscopy}

Cells were grown on collagen coated chamber slides (Falcon) and fixed with $2 \%$ paraformaldehyde in PBS, $\mathrm{pH} 7.4$ for $1 \mathrm{~h}$ at $4{ }^{\circ} \mathrm{C}$. After permeabilization with $0.1 \%$ Triton $\mathrm{X}-100$ and blocking with $2 \%$ non-fat milk, the cells were incubated in a moist chamber at $4^{\circ} \mathrm{C}$ with anti-sera to ARC or pre-immune sera overnight at $4^{\circ} \mathrm{C}$. This was followed by incubation in a dark chamber with the Cy3-conjugated secondary antibody (Jackson ImmunoResearch Laboratories, Inc.) for $2 \mathrm{~h}$ at room temperature. Subsequently, the slides were incubated with the nucleic acid specific stain, 4',6-Diamidino-2-Phenylindole (DAPI) (Sigma).

\section{PC12 survival assay}

Survival was accessed by counting the number of intact nuclei, as described by Greene and coworkers. ${ }^{33}$ Briefly, cells were harvested in PBS, pelleted, and resuspended in detergent-containing lysis buffer. ${ }^{34}$ In this buffer, nuclei of dead cells disintegrate or, if in the process of apoptosis, appear pyknotic and irregularly shaped. In contrast, nuclei of living cells are phase-bright and have clearly defined limiting membranes. Intact nuclei were counted with a hemacytometer and expressed as a percentage of the number of cells initially plated. This method is reported to be comparable to other more laborious methods for detection of survival, such as MTT and Hoechst staining. ${ }^{35,36}$ 


\section{Northern blot analysis}

Total RNA was isolated using RNA STAT (Tel-Test), and poly A $^{+}$RNA obtained with the Poly $A^{+}$Tract mRNA Isolation System III (Promega). The RNA was analyzed by Northern blots as described previously. ${ }^{37}$ The ARC $c$ DNA was labeled with $\left[\alpha{ }^{32} \mathrm{P}\right] \mathrm{dCTP}$ by using the random primer method (Megaprime, Amersham). The labeled probe was heat denatured and $\sim 10^{5} \mathrm{dpm} / \mathrm{ml}$ were incubated with the blot overnight at $42^{\circ} \mathrm{C}$. After hybridization, the blot was washed with $1 \times \operatorname{SSPE}(0.15 \mathrm{M}$ $\mathrm{NaCl}, 10 \mathrm{mM} \mathrm{NaH}_{2} \mathrm{PO}_{4}$, and $1 \mathrm{mM}$ EDTA) and once with $0.1 \times$ SSPE and $1 \%$ SDS at room temperature for $30 \mathrm{~min}$, and exposed to $\mathrm{X}$-ray film.

\section{Transfections}

The transient transfections were carried out using the SuperFect Reagent (Qiagen) as described by the manufacturer's protocol. Briefly, when the cells were $\sim 40 \%$ confluent, the cells were incubated with $5 \mu \mathrm{g}$ of pcDNA3 or pcDNA3-hARC-Flag with a C-terminal Flag (gift from Gabriel Nunez, University of Michigan). After $24 \mathrm{~h}$, some of the cells were subjected to serum withdrawal. All cells were assessed for survival $48 \mathrm{~h}$ after the beginning of transfection.

\section{Acknowledgements}

We gratefully acknowledge Ruth Hogue-Angeletti (Albert Einstein College of Medicine) for preparation of the antisera to ARC, Gabriel Nunez (University of Michigan) for providing the hARC-Flag expression vector and for useful discussion, Lloyd Greene and Leonardis Stephanis (Columbia University) for insightful suggestions including the assay for PC12 cell survival, Sansar Sharna (NY Medical College) for initial help with immunofluorescence, and Bistra Nankova and Frank Traganos (NY Medical College) for their supportive advice and useful ideas.

\section{References}

1. Koseki T, Inohara N, Chen S and Nunez G (1998) ARC, an inhibitor of apoptosis expressed in skeletal muscle and heart that interacts selectively with caspases. Proc. Natl. Acad. Sci. USA 95: 5156-5160

2. Huang B, Eberstadt M, Olejniczak ET, Meadows RP and Fesik SW (1996) NMR structure and mutagenesis of the Fas (APO-1/CD95) death domain. Nature 384: $638-641$

3. Eberstadt M, Huang B, Chen Z, Meadows RP, Ng SC, Zheng L, Lenardo MJ and Fesik SW (1998) NMR structure and mutagenesis of the FADD (Mort1) deatheffector domain. Nature 392: $941-945$

4. Chou JJ, Matsuo H, Duan H and Wagner G (1998) Solution structure of the RAIDD CARD and model for CARD/CARD interaction in caspase-2 and caspase-9 recruitment. Cell 94: 171-180

5. Li P, Nijhawan D, Budihardjo I, Srinivasula SM, Ahmad M, Alnemri ES and Wang X (1997) Cytochrome $c$ and dATP-dependent formation of Apaf-1/caspase-9 complex initiates an apoptotic protease cascade. Cell 91: 479-489

6. Duan H and Dixit VM (1997) RAIDD is a new 'death' adaptor molecule. Nature 385: $86-89$

7. Thornberry NA and Lazebnik Y (1998) Caspases: enemies within. Science 281: $1312-1316$

8. Irmler M, Thome M, Hahne M, Schneider P, Hofmann K, Steiner V, Bodmer JL, Schroter M, Burns K, Mattmann C, Rimoldi D, French LE and Tschopp J (1997) Inhibition of death receptor signals by cellular FLIP. Nature 388: 190-195

9. Geertman R, McMahon A and Sabban EL (1996) Cloning and characterization of cDNAs for novel proteins with glutamic acid-proline dipeptide tandem repeats. Biochim. Biophys. Acta. 1306: 147-152
10. Ekhterae D, Lin Z, Lundberg MS, Crow MT, Brosius 3rd FC and Nunez G (1999) ARC inhibits cytochrome $c$ release from mitochondria and protects against hypoxia-induced apoptosis in heart-derived H9c2 cells. Circ. Res. 85: e70-e77

11. Ashkenazi A and Dixit VM (1998) Death receptors: signaling and modulation. Science 281: $1305-1308$

12. Stefanis L, Troy CM, Qi H, Shelanski ML and Greene LA (1998) Caspase-2 (Nedd-2) processing and death of trophic factor-deprived PC12 cells and sympathetic neurons occur independently of caspase-3 (CPP32)-like activity. J. Neurosci. 18: $9204-9215$

13. Troy CM, Stefanis L, Greene LA and Shelanski ML (1997) Nedd2 is required for apoptosis after trophic factor withdrawal, but not superoxide dismutase (SOD1) downregulation, in sympathetic neurons and PC12 cells. J. Neurosci. 17: 1911 1918

14. Haviv R, Lindenboim L, Yuan J and Stein R (1998) Need for caspase-2 in apoptosis of growth-factor-deprived PC12 cells. J. Neurosci. Res. 52: 491-497

15. Greene LA (1978) Nerve growth factor prevents the death and stimulates the neuronal differentiation of clonal PC12 pheochromocytoma cells in serum-free medium. J. Cell. Biol. 78: 747-755

16. Mesner PW, Epting CL, Hegarty JL and Green SH (1995) A timetable of events during programmed cell death induced by trophic factor withdrawal from neuronal PC12 cells. J. Neurosci. 15: 7357-7366

17. Rukenstein A, Rydel RE and Greene LA (1991) Multiple agents rescue PC12 cells from serum-free cell death by translation- and transcription-independent mechanisms. J. Neurosci. 11: 2552-2563

18. Mesner PW, Winters TR and Green SH (1992) Nerve growth factor withdrawalinduced cell death in neuronal PC12 cells resembles that in sympathetic neurons. J. Cell. Biol. 119: 1669-1680

19. Shearwin-Whyatt LM, Harvey NL and Kumar S (2000) Subcellular localization and CARD-dependent oligomerization of the death adaptor RAIDD. Cell Death Differ. 7: $155-165$

20. Mancini M, Machamer CE, Roy S, Nicholson DW, Thornberry NA, CasciolaRosen LA and Rosen A (2000) Caspase-2 is localized at the Golgi complex and cleaves golgin-160 during apoptosis. J. Cell Biol. 149: 603-612

21. Zhivotovsky B, Samali A, Gahm A and Orrenius S (1999) Caspases: their intracellular localization and translocation during apoptosis. Cell Death Differ. 6 : $644-651$

22. Orlowski RZ (1999) The role of the ubiquitin-proteasome pathway in apoptosis Cell Death Differ. 6: 303-313

23. Siegel RM, Martin DA, Zheng L, Ng SY, Bertin J, Cohen J and Lenardo MJ (1998) Death-effector filaments: novel cytoplasmic structures that recruit caspases and trigger apoptosis. J. Cell Biol. 141: 1243-1253

24. Sanchez I, Xu CJ, Juo P, Kakizaka A, Blenis J and Yuan J (1999) Caspase-8 is required for cell death induced by expanded polyglutamine repeats. Neuron 22 : $623-633$

25. Perez D and White E (1998) E1B 19K inhibits Fas-mediated apoptosis through FADD-dependent sequestration of FLICE. J. Cell Biol. 141: 1255-1266

26. Jaunin F, Burns K, Tschopp J, Martin TE and Fakan S (1998) Ultrastructural distribution of the death-domain-containing MyD88 protein in HeLa cells. Exp. Cell Res. 243: $67-75$

27. Mao PL, Jiang Y, Wee BY and Porter AG (1998) Activation of caspase-1 in the nucleus requires nuclear translocation of pro-caspase- 1 mediated by its prodomain. J. Biol. Chem. 273: 23621-23624

28. Krajewski S, Krajewska M, Ellerby LM, Welsh K, Xie Z, Deveraux L, Salvesen GS, Bredesen DE, Rosenthal RE, Fiskum G and Reed JC (1999) Release of caspase-9 from mitochondria during neuronal apoptosis and cerebral ischemia. Proc. Natl. Acad. Sci. USA 96: 5752-5757

29. Colussi PA, Harvey NL and Kumar S (1998) Prodomain-dependent nuclear localization of the caspase-2 (Nedd2) precursor. A novel function for a caspase prodomain. J. Biol. Chem. 273: 24535-24542

30. Troy CM, Rabacchi SA, Friedman WJ, Frappier TF, Brown K and Shelanski ML (2000) Caspase-2 mediates neuronal cell death induced by beta-amyloid. J. Neurosci. 20: 1386-1392

31. Hiremagalur B, Nankova B, Nitahara J, Zeman R and Sabban EL (1993) Nicotine increases expression of tyrosine hydroxylase gene: Involvement of protein kinase A-mediated pathway. J. Biol. Chem. 268: 23704-23711 
32. Pittman RN, Wang S, DiBenedetto AJ and Mills JC (1993) A system for characterizing cellular and molecular events in programmed neuronal cell death. J. Neurosci. 13: $3669-3680$

33. Batistatou A and Greene LA (1991) Aurintricarboxylic acid rescues PC12 cells and sympathetic neurons from cell death caused by nerve growth factor deprivation: correlation with suppression of endonuclease activity. J. Cell Biol. 115: 461-471

34. Soto AM and Sonnenschein C (1985) The role of estrogens on the proliferation of human breast tumor cells (MCF-7). J. Steroid Biochem. 23: 87-94
35. Farinelli SE and Greene LA (1996) Cell cycle blockers mimosine, ciclopirox, and deferoxamine prevent the death of PC12 cells and postmitotic sympathetic neurons after removal of trophic support. J. Neurosci. 16: 1150-1162

36. Stefanis L, Park DS, Friedman WJ and Greene LA (1999) Caspase-dependent and -independent death of camptothecin-treated embryonic cortical neurons. J. Neurosci. 19: 6235-6247

37. Gueorguiev VD, Zeman RJ, Hiremagalur B, Menezes A and Sabban L (1999) Differing temporal roles of $\mathrm{Ca} 2+$ and cAMP in nicotine-elicited elevation of tyrosine hydroxylase mRNA. Am. J. Physiol. 276: C54-C65 